\title{
La Iglesia católica en la lucha por la contrarreforma religiosa en México
}

\author{
Tania Hernández Vicencio
}

Este trabajo plantea una primera reflexión sobre el proceso político que hizo en México posible la aprobación de la reforma al artículo 24 constitucional, sobre la libertad de cultos, en el Congreso de la Unión. El argumento a favor, basado en la defensa de la libertad religiosa como parte de un nuevo discurso de la modernidad y los derechos humanos, fue eficiente en dos sentidos: consolidó la idea de que el moderno Estado laico debe procurar nuevas condiciones para avanzar en el ejercicio de la libertad religiosa y dio sustento en los hechos a una alianza entre los sectores conservadores de las elites eclesiástica y política en un contexto de intercambio de apoyos electorales por mayores ventajas para la Iglesia católica.

PALABRAS CLAVE: reforma constitucional, libertad religiosa, laicidad, alianzas, católicos conservadores

\section{The Catholic Church in the Struggle for the Religious Reformation in Mexico}

This work raises the first reflection on the political process that made possible in Mexico the approval of the reform to the $24^{\text {th }}$ constitutional article, about the freedom of worships, in the Congress of the Union. The argument supporting the defense of the religious freedom as part of a new speech of modernity and human rights was efficient in two senses: it consolidated the idea that modern lay State must try new conditions to advance in the exercise of religious freedom, and gave sustenance in the facts to an alliance between the conservative sectors of ecclesiastic and political elite, in a context of electoral supports exchange for major advantages for the Catholic Church.

KEYWORDS: constitutional reform, religious freedom, laicism, alliances, conservative catholics

Tania Hernández Vicencio: Dirección de Estudios Históricos, Instituto Nacional de Antropología e Historia,

Distrito Federal, México

thernandez.deh@inah.gob.mx

Desacatos, núm. 44, enero-abril 2014, pp. 143-158

Recepción: 3 de junio de 2012 / Aceptación: 28 de junio de 2013 


\section{INTRODUCCIÓN}

$\mathrm{L}$ a aprobación de la iniciativa de reforma del artículo 24 constitucional, relativo a la libertad de cultos, en el Congreso de la Unión en 2012 fue resultado de una larga lucha de los sectores conservadores del catolicismo mexicano durante el siglo pasado. El origen de esta movilización se remonta -en una perspectiva de largo alcance- al proceso de reforma liberal en la segunda mitad del siglo XIX y posteriormente a la consolidación del principio de laicidad que se estableció en la Constitución de 1917. Desde ese momento los sectores conservadores de la Iglesia católica y sus grupos de laicos impugnaron el artículo $24,{ }^{1}$ en el que se garantizó la libertad de los individuos para ejercer su $\mathrm{fe}^{2}$ como expresión de su libertad religiosa, pero también se reafirmó la supremacía del Estado en la regulación de los actos de culto público. ${ }^{3}$

Este trabajo es una primera reflexión sobre la etapa más reciente de ese largo proceso, en la cual se conjuntaron elementos favorables al cambio constitucional. En los dos primeros apartados delineo algunos de los principales rasgos del contexto político y social que desde la última década del siglo xx configuraron el escenario propicio para impulsar la reforma del artículo 24, y en la tercera parte analizo

\footnotetext{
${ }^{1}$ Otros artículos impugnados por el catolicismo conservador han sido: el 3, en el que quedó consignada la laicidad de la educación pública; el 5, en el que se negó la existencia de órdenes monásticas en México; el 27, que restringió la posesión de bienes de la Iglesia católica, y el 130, que no reconoció la personalidad jurídica de las iglesias, lo que afectó fundamentalmente a la católica, como iglesia mayoritaria.

${ }^{2}$ El artículo 24 de la Constitución de 1917 mantuvo el espíritu de la Ley de Libertad de Cultos del 4 de diciembre de 1860. Véase Constitución Política de la República Mexicana de 1857.

${ }^{3}$ El texto original del artículo 24 decía: “Todo hombre es libre para profesar la creencia religiosa que más le agrade y para practicar las ceremonias, devociones o actos de culto respectivo, en los templos o en su domicilio particular, siempre que no constituyan un delito o falta penados por la ley. Todo acto religioso de culto público deberá celebrarse precisamente dentro de los templos, los cuales estarán siempre bajo la vigilancia de la autoridad". Véase Constitución Política de los Estados Unidos Mexicanos, que reforma la de 5 de febrero de 1857.
}

las características de la movilización que reinició en 2011. La idea central es que la defensa de la libertad religiosa fue exitosa en esta última fase en el terreno argumentativo por ser parte de la reedición del discurso de la modernización, que lanzó un sector importante de la clase política, ${ }^{4}$ que en el terreno de lo religioso retomó el debate sobre las funciones del Estado social moderno en relación con los derechos humanos. Por otro lado, en los hechos, el progreso de la iniciativa debe verse como parte de una agenda de negociaciones implícitas y explícitas entre sectores específicos de las elites de los principales partidos nacionales, en el marco del proceso electoral de 2012, cuando se disputó la presidencia de la república.

La amplia expectativa del Partido Revolucionario Institucional (PRI) de ganar las elecciones, después de dos erráticos gobiernos encabezados por el Partido Acción Nacional (PAN), creó las condiciones favorables para que la Iglesia católica introdujera en el debate público una añeja demanda, pero ahora con amplias posibilidades de concretarse en el marco del intercambio de bienes políticos. Tras probar suerte con Acción Nacional durante dos sexenios sin tener éxito en la concreción de la reforma, la Iglesia católica volvió los ojos al PRI, su viejo aliado político, que le ayudaría a dar los últimos pasos para recuperar privilegios y avanzar en su regreso como actor político, en un contexto de pérdida paulatina de adeptos. ${ }^{5}$

\section{PRIMEROS FRUTOS DE UNA COALICIÓN CONSERVADORA (1988- 1999)}

Carlos Salinas de Gortari llegó al poder en 1988 con un alto nivel de ilegitimidad, pues la elección presidencial de ese año estuvo manchada por la denuncia

\footnotetext{
${ }^{4}$ La clase política se integra con las elites económica, política, cultural, militar y religiosa de un país (Mosca, 1986). Constituye un ente cohesionado por una red de relaciones sociales y de intereses específicos que abonan a su reproducción, por lo que tiende a compartir una visión general sobre el proyecto nacional.

${ }^{5}$ Según el Censo de Población de 2010, los católicos en México representaban $83.9 \%$ de la población, lo que significaba una caída de más de 4 puntos respecto de 2000 (INEGI, 2010).
} 
de fraude por parte del candidato presidencial de la izquierda, Cuauhtémoc Cárdenas, que en algún momento incluso fue respaldada por el candidato de la derecha partidista Manuel J. Clouthier a través del PAN. El afianzamiento del proyecto neoliberal requería nuevas alianzas, por lo que el eje de la política interna fue la interlocución con actores clave de la oposición, como la cúpula empresarial, Acción Nacional y la alta jerarquía de la Iglesia católica que se reposicionaba poco a poco como un actor clave en los procesos políticos locales, de forma más clara, desde 1986. Estos actores serían importantes para echar a andar lo que el presidente Salinas llamó el "proyecto modernizador" del país. En su toma de posesión, afirmó:

Un Estado moderno es aquel que garantiza la seguridad de la nación y que sabe modernizar su relación con los partidos políticos, con los sindicatos, con los grupos empresariales, con la Iglesia, y con las nuevas organizaciones del campo y las ciudades (Samaniego y Aranda, 1988)

En este sentido, se avanzó en la liberalización del mercado nacional, al PAN se le concedió un lugar privilegiado como parte de la oposición política y se puso al día la relación entre el Estado y las iglesias, en especial con la católica. Se afianzaron los lazos con un sector minoritario pero poderoso que se consolidó con Girolamo Prigione, delegado apostólico en México de 1978 a 1992 y nuncio apostólico de 1992 a 1997. Prigione condicionó el comportamiento de la Iglesia al logro de los cambios constitucionales (Masferrer, 2000: 27). Cuando nadie lo esperaba, los representantes de la Iglesia católica asistieron como invitados especiales a la ceremonia republicana de toma de protesta del presidente. Dicho acto abrió para la institución eclesiástica una nueva ruta hacia el espacio público. La convocatoria resultaba un acto favorable para la jerarquía de la Iglesia católica en general. En aquella ocasión, el líder del Episcopado Mexicano, Adolfo Suárez Rivera, declaraba:
Asistimos gustosos porque creemos que esta invitación significa un cambio en la modernidad, una aproximación al diálogo y a la mejor comprensión de todos. La modernidad debe traer un poco de apertura, esperanza, diálogo y oportunidad de participación (Samaniego y Aranda, 1988).

La presencia de importantes miembros de la elite eclesiástica abonó a la legitimidad nacional e internacional del nuevo jefe del Ejecutivo e inició un proceso de negociación sobre un nuevo estatus para la Iglesia católica en la vida política. En febrero de 1989 la estrategia política de los dirigentes católicos encontró un fuerte aliciente en el mensaje emitido por el Papa Juan Pablo II. El escrito fue enviado a los obispos mexicanos en el marco del informe de Visita ad Limina, por lo que su contenido recordaba las encíclicas papales de otros tiempos, en las que se atacaba al artículo 130 constitucional y se demandaba la libertad religiosa (Mendoza, 1989). En ese entonces, la reactivación política de la elite de la Iglesia católica ya no respondía a medidas gubernamentales anticlericales o antirreligiosas, pero sí a un nuevo intento de El Vaticano y de sus principales jerarcas en México para mejorar su posición frente al Estado, ahora con base en una alianza con el sector católico conservador de la clase política mexicana y de la sociedad civil. El reclamo de la jerarquía eclesiástica sobre el reconocimiento de los derechos cívicos del clero y sobre la libertad religiosa cobró mayor relevancia en el contexto de un nuevo impulso al tema de los derechos humanos. ${ }^{6}$ Esta estrategia pretendía trascender la discusión estrictamente relacionada con la laicidad del Estado mexicano que antaño había quedado restringida al ámbito de la negociación entre la elite de la Iglesia y la política. El alto clero buscaba, en principio, reorientar la discusión hacia el debate internacional, en particular sobre los rasgos que debía tener un Estado moderno como garante de los derechos humanos, pero sobre todo

${ }^{6}$ Este discurso fue cobrando fuerza en el pAN desde mediados de la década de 1960, a propósito de los resultados del Concilio Vaticano II. 
- como se verá a continuación - buscaba avanzar en la demanda de nuevos privilegios. En el transcurso de los meses siguientes el Episcopado Mexicano hizo llegar al presidente de la república, a la Secretaría de Gobernación y a las Cámaras de Diputados y de Senadores varias consideraciones para modificar la Carta Magna. Al respecto, Manuel Talamás Camandri, obispo de Ciudad Juárez, diría:

No es el voto a los curas, que representa una cuestión elemental de derechos humanos, lo que la Iglesia quiere con el reconocimiento jurídico es el derecho a la posesión de bienes, a la organización institucional, a la búsqueda de métodos de subsistencia y acceso a los medios electrónicos de comunicación. Queremos libertad para la prédica de un evangelio crítico, que cuestione a todos y permita descubrir errores en su ideología, desviaciones y corrupción de su conducta, lo mismo en la vida pública que en la vida privada. Después del sectarismo antirreligioso, que ha caracterizado la actitud oficial en la última centuria, consecuencia de los prejuicios que infectan la historia de México, el proceso de corrección ya se ha iniciado. Reconocemos ese mérito de Carlos Salinas de Gortari de querer empezar a enmendar estos errores (Mendoza, 1989).

En febrero de 1990, Agustín Téllez Cruces fue nombrado representante del presidente de la república ante el Papa, como un signo de acercamiento, que sin embargo el entonces secretario de Gobernación, Fernando Gutiérrez Barrios, se apresuró a matizar con la afirmación de que el gobierno mexicano mantenía "incólumes historia, tradición y principios", por lo que no se consideraba la reforma a los artículos de la Constitución relativos a su relación con el clero (Armenta, 1990). A pesar de estas declaraciones, en mayo del mismo año, Juan Pablo II fue recibido por el presidente Salinas de Gortari durante su segunda visita a México.

La benéfica relación que la elite de la Iglesia había logrado establecer con la Presidencia de la República quedó de manifiesto el 10 de diciembre de 1991, cuando el jefe del Ejecutivo Federal hizo llegar al Congreso de la Unión, por medio de los diputados del PRI, una iniciativa de reformas a la Constitución que sería aprobada siete días después. Las reformas constitucionales en materia religiosa aparecieron publicadas en el Diario Oficial de la Federación el 28 de enero de 1992. El centro de éstas fue el artículo 130 constitucional, en el que se reconoció la personalidad jurídica a las instituciones religiosas, lo que por supuesto benefició a la Iglesia católica. En el caso del artículo 24, la reforma incluyó tres novedades: los templos dejaron de ser el único lugar donde podían profesarse los actos de culto público, lo que abrió la posibilidad de realizar actos religiosos de forma extraordinaria fuera de éstos. Se agregó la garantía de que el Congreso no dictara leyes que instituyeran o prohibieran religión alguna y se eliminó la prescripción de que - como establecía el contenido original de este artículo- los templos estuvieran bajo la vigilancia de la autoridad. ${ }^{7}$ La actitud del gobierno mexicano y las reformas constitucionales allanaron el camino para la reanudación de las relaciones entre el Estado mexicano y El Vaticano. ${ }^{8}$ El 24 de noviembre de ese año Girolamo Prigione asumió la Nunciatura Apostólica, lo que mostró el reconocimiento de la Santa Sede a su trabajo de acercamiento y negociación con el gobierno mexicano, pero también profundizó el clima de tensión al interior de la elite de la Iglesia. ${ }^{9}$ A partir de ese momento se perfilaron con mayor nitidez tres tendencias: "la dialoguista", "la rupturista" y "la que buscaba nuevos equilibrios entre la Iglesia y el Estado". Esta última

\footnotetext{
${ }^{7}$ Sobre las reformas que ha sufrido el artículo 24 véase el cuadro 1. ${ }^{8}$ Antecedentes del acercamiento entre el gobierno mexicano y la Santa Sede fueron el encuentro en febrero de 1974 entre Luis Echeverría y el Papa Pablo VI, el recibimiento de José López Portillo al Papa Juan Pablo II, en enero de 1979, en su primera visita a México, el tratamiento especial que Salinas de Gortari dio al Papa en su regreso a México en 1990 y la visita que hizo al Vaticano en julio de 1991, en el marco de su gira por Europa.

${ }^{9}$ Las rivalidades entre los obispos mexicanos se profundizaron con la confrontación entre el Nuncio Apostólico y el arzobispo Ernesto Corripio Ahumada. La politización de la Iglesia católica a partir de 1988 era producto de su participación en asuntos político-electorales y de la exposición pública de sus conflictos internos (Loaeza, 1996: 122-123).
} 
Cuadro 1. Evolución del texto del artículo 24 constitucional

Redacción del artículo 24

en la Constitución de 1917
"Todo hombre es libre para profesar la creencia religiosa que más le agrade y para practicar las ceremonias, devociones o actos de culto respectivo, en los templos o en su domicilio particular, siempre que no constituyan un delito o falta penados por la ley. Todo acto religioso de culto público, deberá celebrarse precisamente dentro de los templos, los cuales estarán siempre bajo la vigilancia de la autoridad".
Redacción del artículo 24 después de la reforma de enero de 1992
“Todo hombre es libre para profesar la creencia religiosa que más le agrade y para practicar las ceremonias, devociones o actos del culto respectivo, siempre que no constituyan un delito o falta penados por la ley. El Congreso no puede dictar leyes que establezcan o prohíban religión alguna. Los actos religiosos de culto público se celebrarán ordinariamente en los templos. Los que extraordinariamente se celebren fuera de éstos se sujetarán a la ley reglamentaria".
Redacción de la propuesta de reforma del artículo 24 enviada por el diputado priista José Ricardo López Pescador el 18 de marzo de 2010
"Todo individuo tiene derecho a la libertad de conciencia y de religión, este derecho incluye la libertad de tener o adoptar, o no tener ni adoptar, la religión o las creencias de su elección, así como la libertad de manifestar su religión o creencias, individual o colectivamente, tanto en público como en privado, mediante el culto, la celebración de ritos, las prácticas, la difusión y la enseñanza; siempre que no constituyan un delito o una falta sancionados por la ley.

[...]

[Se deroga]

Sin contravenir lo prescrito en el artículo $3^{\circ}$ de esta Constitución, el Estado respetará la libertad de los padres y, en su caso, de los tutores legales para garantizar que los hijos reciban la educación religiosa y moral que esté de acuerdo con sus propias convicciones".
Redacción definitiva del artículo 24, después de haber sido aprobada por el Congreso de la Unión, en abril de 2012, y enviada a los congresos locales para su discusión y aprobación. De obtener la mayoría más uno de la votación en las legislaturas estatales, éste será el contenido de dicho artículo en la Constitución Federal
"Toda persona tiene derecho a la libertad de convicciones éticas, de conciencia y de religión, y a tener o adoptar en su caso, la de su agrado. Esta libertad incluye el derecho de participar, individual o colectivamente, tanto en público como en privado, en las ceremonias, devociones o actos de culto respectivo, siempre que no constituyan un delito o falta penados por la ley. Nadie podrá utilizar los actos públicos de expresión de esta libertad con fines políticos, de proselitismo o de propaganda política.

El Congreso no puede dictar leyes que establezcan o prohíban religión alguna.

Los actos religiosos de culto público se celebrarán ordinariamente en los templos. Los que extraordinariamente se celebren fuera de éstos se sujetarán a la ley reglamentaria”. 
representaba a la mayoría de los sacerdotes y veía con desconfianza a quienes pretendían un acercamiento con el gobierno (Masferrer, 2000: 265).

Para el segundo lustro de la década de 1990, la coalición conservadora se expresaba con toda nitidez. Su conformación había sido producto de dos procesos: por un lado, el ascenso y reacomodo de la derecha política y social y, por otro, el afianzamiento del sector tecnócrata del gobierno priista (Hernández, 2009). Dicho contexto favoreció que la Iglesia católica reiniciara una serie de actividades. En noviembre de 1996, durante la IX Asamblea Nacional de Pastoral Educativa del Episcopado, se dio a conocer una campaña para "moralizar" los medios de comunicación, que se puso en marcha en 1997. Además, cobró importancia la discusión de la defensa de la vida humana desde la concepción y hasta la muerte natural, se insistió en el reclamo del derecho de las familias a decidir sobre el tipo de educación que se impartía a los hijos y, por supuesto, se volvió sobre la demanda de libertad religiosa.
En junio de ese año llegó a México el segundo nuncio apostólico, Justo Mullor, cercano al Opus $D e i$, quien se enfrentó a las tensiones que existían entre los grupos de la elite de la Iglesia católica, los cuales luchaban por la redefinición de su nuevo liderazgo. Mullor intentó crear las condiciones para la estabilización institucional de las relaciones entre la Iglesia y el Estado, por lo que buscó disminuir el protagonismo del sector de la Iglesia que había establecido alianzas evidentes con el grupo de neoliberales en el gobierno, el cual había sido impulsado por el anterior nuncio. Los esfuerzos de Mullor fueron en vano, ya que tres años después de su llegada a México, luego de una serie de presiones de los sectores más cercanos a Prigione y a los Legionarios de Cristo, fue requerido en Roma.

Para el final de la década de 1990, el PAN ya había mostrado que era capaz de articular a un importante sector de la oposición. Junto a la activa participación de organizaciones cívicas de ideología conservadora y los principales organismos empresariales del país, este partido vinculó varias acciones en torno a la idea de la moralización de la vida política. El candidato presidencial del PAN, Vicente Fox Quesada, en su campaña presidencial de 1999 lanzó un mensaje con doble contenido. Aprovechó el discurso de la democracia y el cambio para resaltar lo que consideraba la competencia inequitativa entre las iglesias y ofreció regular el papel de las mismas, además de impulsar "la libertad de creencias". Más que interesarse en garantizar la expresión de la pluralidad religiosa que experimentaba el país, Fox envió el mensaje a la jerarquía de la Iglesia católica de que le convenía apoyarlo en el terreno electoral (Blancarte, 2004: 12).

\section{EL CAMINO HACIA LA REFORMA (2000-2009)}

En un evento organizado por el Instituto Mexicano de Doctrina Social Cristiana (Imdosoc), a fines de la década de 1990, abogados, políticos y académicos, la mayoría de filiación católica, ${ }^{10}$ se manifestaron a favor de avanzar de "un Estado laico anticlerical [vigente hasta la caída del Porfiriato] pasando por un Estado laico de corte antirreligioso [que se instaura en la Constitución de 1917] a un Estado laico orientado a la libertad religiosa”. Ésta, en su opinión, correspondía a la concepción moderna del Estado laico, en la que se integraban tanto la teoría general de los derechos humanos como los instrumentos internacionales en esta materia y la doctrina social de la Iglesia católica, explícita en la Declaración sobre la libertad religiosa, Dignitatis Humanae, promulgada por el Concilio Vaticano II. ${ }^{11}$

\footnotetext{
10 Entre los participantes estuvieron Efraín González Morfín miembro del PAN, y Raúl González Schmal, exmilitante del mismo partido. Dos documentos importantes para la argumentación sobre la reforma del artículo 24 fueron el del sacerdote Antonio Molina y el de González Schmal.

${ }^{11}$ A mediados de 1989, el Imdosoc organizó un ciclo de conferencias con el título "Las relaciones Iglesia-Estado-sociedad: 100 años de relación ambigua”. De ahí surgió una comisión permanente denominada Comisión de Relaciones Iglesia-Estado, que a partir de 1992, con la reforma del artículo 130, amplió su tarea y pasó a llamarse Comisión de Libertad Religiosa.
} 
Para este grupo, el reconocimiento de los derechos humanos y la libertad religiosa como parte de éstos sería uno de los elementos sustantivos de un Estado social y democrático de derecho (Molina, 1999: 54), que debería asumir el fenómeno religioso como un componente positivo de la sociedad y promover las condiciones para que la libertad religiosa sea real y efectiva (Molina, 1999: 64). El principio de libertad religiosa debía ser considerado un principio de organización social y configuración política clave para superar la "discordia histórica" entre mexicanos (González, 1999: 103), por lo que un verdadero Estado laico sería aquel que promoviera el ejercicio de todas las dimensiones de la libertad religiosa (González, 1999: 109), a saber: la libertad de conciencia, la libertad de culto, la libertad de difusión de credos, ideas u opiniones religiosas, el derecho a la formación religiosa de los miembros de la confesión, la libertad de enseñanza y el derecho a la educación, el derecho de reunión y manifestación con finalidad religiosa y el derecho de asociación religiosa (González, 1999: 114-116). Sólo así, se afirmaba, la sociedad mexicana podría avanzar del laicismo excluyente, según el cual la religiosidad es fruto de la irracionalidad y el oscurantismo, e incluso de un laicismo neutral e indiferente, a una nueva laicidad abierta, digna del siglo xxi (González, 1999: 75). El principio que debía articular la función de un Estado moderno y democrático, que aspirase a un sistema de relaciones como en las democracias europeas - Italia, España y Alemania, eran los ejemplos-, sería la cooperación, por lo que debían removerse los obstáculos que dificultaran el libre desarrollo de los derechos ciudadanos y, más aun, debía promoverse el financiamiento de la libertad religiosa (González, 1999: 79 y 86).

El 29 de febrero de 2000 se confirmó que el nuevo representante del Papa en México era monseñor Leonardo Sandri, que fortalecería la cruzada moral de la Iglesia católica en el país. El 27 de abril de ese año, en el marco de la LXIX Asamblea Plenaria de la Conferencia del Episcopado Mexicano, siendo aún candidato presidencial, el panista Vicente Fox envió cartas personales a 120 obispos y al nuncio apostólico; además, publicó un documento con sus compromisos de campaña para congraciarse con la representación vaticana y obtener su apoyo en el contexto de los comicios federales. En el documento enviado a Leonardo Sandri se hacía referencia a los artículos de la Constitución que el candidato - de llegar a ser presidente- se comprometía a modificar:

Muy estimado Monseñor: Ante el evento, cada día más cercano y factible, de la alternancia en el poder en nuestro país con el acceso de un servidor a la Presidencia de la República, estimo que es muy conveniente que usted conozca de primera mano los planteamientos contenidos en mi Proyecto para la Nación sobre Libertad Religiosa y Relaciones Iglesia-Estado [...]

5. Responderé al interés manifestado por las iglesias para promover un amplio espacio de libertad religiosa a partir del artículo 24 constitucional.

6. En congruencia con el derecho humano a la libertad religiosa y con los acuerdos internacionales suscritos por México en esta materia, promoveré que se eliminen las contradicciones entre los artículos 4 y 130 de la Constitución, reformando el 130 en la parte que restringe la libertad religiosa, que proclama el artículo 24 .

7. Abriré el acceso a los medios de comunicación a las iglesias, para que éstas puedan difundir sus principios y actividades.

8. Promoveré que en el marco de una reforma hacendaria integral se defina un régimen fiscal para las iglesias, con deducibilidad de impuestos, cuando contribuyan al desarrollo humano. ${ }^{12}$

Seis años más tarde, en el contexto de las elecciones presidenciales de 2006, el candidato presidencial panista Felipe Calderón también se pondría a disposición de los jerarcas de la Iglesia católica y como parte de su agenda en el tema religioso prometería a su vez avanzar en la reforma del artículo 24. Pero la disputa por la redefinición del significado del Estado laico se reactivó con vigor a partir de abril de 2007 ,

${ }^{12}$ Los diarios Reforma y La Jornada publicaron la carta el 30 de abril de 1999. 


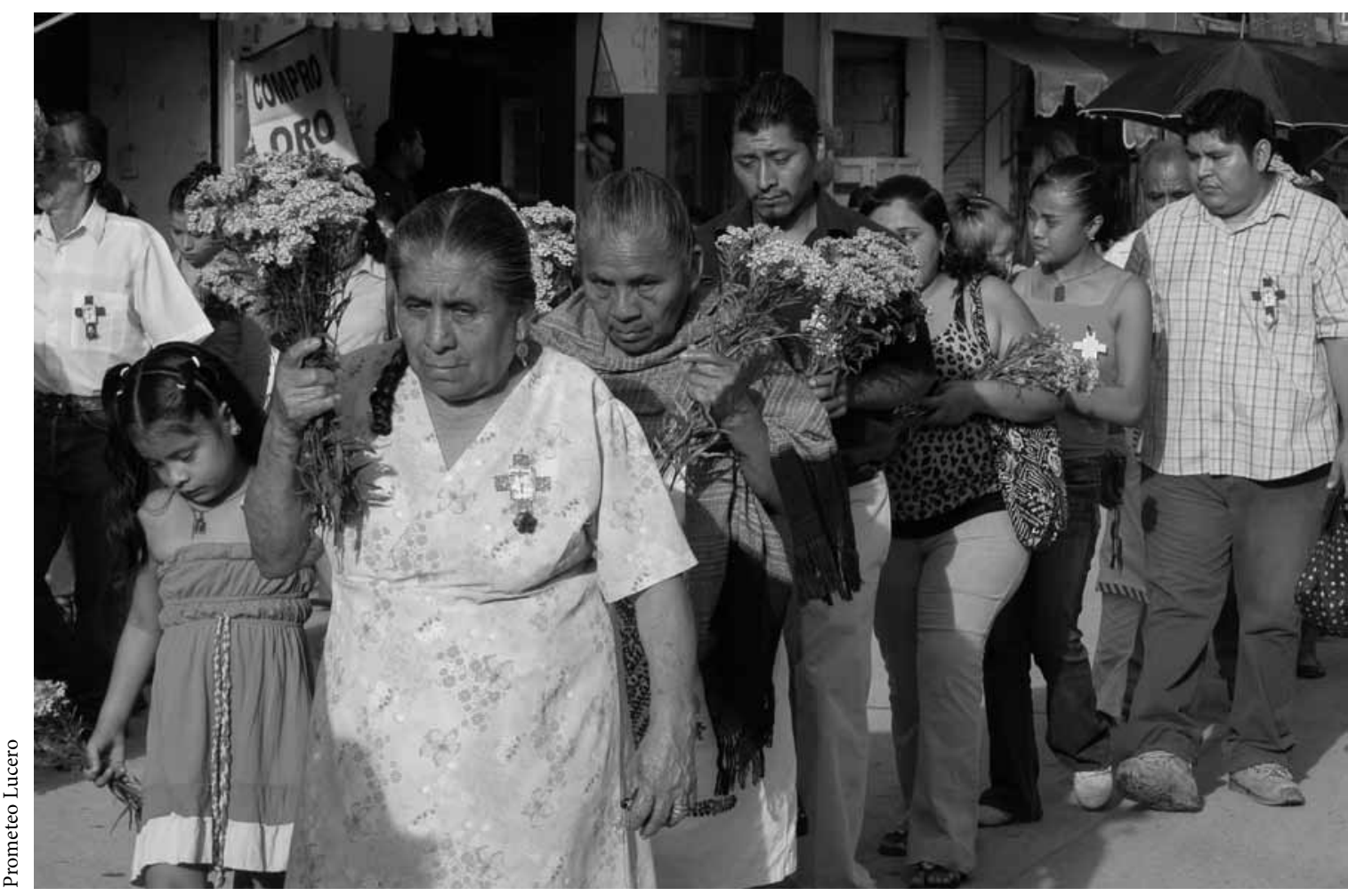

Festividad previa al Señor del Nicho en Tlapa, Guerrero. Durante tres semanas se realizan procesiones por las calles hasta el 23 de octubre, ocasión para la que éstas se tapicen de aserrín.

cuando en la capital del país - caja de resonancia de muchos de los procesos políticos y sociales a nivel nacional- se aprobaron varias reformas a la Ley de Salud y al Código Penal, con el fin de despenalizar el aborto durante las 12 primeras semanas de embarazo (Hernández, 2011). ${ }^{13}$ Inicialmente la propuesta había sido presentada el 26 de noviembre de 2006 por el diputado priista Armando Tonatiuh González Case, y fue secundada por diputados del Partido de la Revolución Democrática (PRD) y del Partido Social Demócrata (PSD). Así las cosas, en un contexto en el que se operaba una apertura importante en el terreno de la política pública de salud, la movilización de la jerarquía eclesiástica y de varios de sus grupos de laicos no se hizo esperar.

\footnotetext{
${ }^{13} \mathrm{El}$ antecedente inmediato de esta reforma era la denominada Ley Robles, aprobada el 18 de agosto de 2000.
}

El 25 de marzo de 2007 la Arquidiócesis, la Unión Nacional de Padres de Familia (UNPF) y la organización Somos Vida llevaron a cabo la primera peregrinación a la Basílica de Guadalupe. ${ }^{14}$ La Iglesia católica lograría sumar a varios grupos protestantes e incluso a miembros del Ejército Mexicano, mostrando su rechazo a un nuevo cambio de la ley que avanzara en la despenalización del aborto. A partir de entonces, expresiones de fuerza como ésta, que durante muchos años fueron impensables en el marco del proceso de secularización de la sociedad y las instituciones mexicanas, se tornaron parte de la escena pública. La Arquidiócesis, encabezada por el cardenal Norberto Rivera, fijó la postura de los obispos

\footnotetext{
${ }^{14}$ La manifestación se desarrolló en el marco del III Congreso Internacional Provida, celebrado en la ciudad de México del 23 al 25 de marzo de 2007.
} 
mexicanos a partir de un documento elaborado en 1999 en el que se hacía un llamado a los católicos a "no votar por las fuerzas políticas que no respetan ni defienden la vida". El activismo político de la elite de la Iglesia católica fue solapado por las autoridades civiles, que permitieron que sus dirigentes confrontaran el orden constitucional. A la reacción en contra de la reforma incluso se sumaron varios integrantes de primer nivel del gobierno federal de origen panista, en un contexto en el que el presidente de la república, Felipe Calderón, se limitó a decir que personalmente estaba "a favor de la vida". En 2008 se llevaron a cabo varias reformas a las constituciones locales de algunas entidades del país, que fueron apuntaladas por el PAN y el PRI, en las que se criminalizaba la práctica del aborto. A pesar de las fuertes tensiones sociales que se generaron, un año después el presidente Calderón volvería a expresar su apoyo a la movilización de los grupos católicos, cuando en enero se presentó a inaugurar el Congreso Teológico Pastoral del VI Encuentro Mundial de las Familias, realizado en la ciudad de México (Calderón, 2009).

En las elecciones intermedias de 2009, el PAN perdió sus principales bastiones regionales (Hernández, 2012) y el PRI repuntó en los resultados electorales de la mayoría de los territorios que perdía Acción Nacional. El gobierno federal era severamente cuestionado por la sociedad civil debido a los resultados de su fallida política contra el narcotráfico y su falta de logros en el terreno de la generación de empleos, por lo que se complicó el panorama para el PAN hacia la elección presidencial de 2012. El PRI, por su parte, comenzó a aparecer en la escena política como un partido con experiencia de gobierno y con capacidad para recomponer los acuerdos con los principales actores nacionales. En ese contexto, la alta jerarquía de la Iglesia católica y especialmente la Arquidiócesis de la Ciudad de México, que hasta ese momento había fungido como un aliado importante del gobierno de Calderón, comenzó a replantear su estrategia de construcción de alianzas. El semanario Desde la Fe, órgano informativo de la Arquidiócesis, se convirtió en un espacio de crítica al desempeño del gobierno, cuestionó en particular el papel de los funcionarios y destacó los magros resultados de las políticas públicas del gobierno federal. Al mismo tiempo, la Conferencia del Episcopado Mexicano (CEM) aprovechó los resultados de la discusión de la Asamblea Plenaria de Obispos, realizada en noviembre de 2011, para reactivar sus propuestas y estrategias en el terreno de la política educativa, para lo cual publicó el documento denominado Educar para una nueva sociedad. Reflexiones y orientaciones sobre la educación en México. ${ }^{15}$

\section{EL CIERRE DE UN CICLO (20 I0-20 I3)}

La complejidad que fue adquiriendo el proceso político hizo que también los sectores progresistas en el Congreso de la Unión reaccionaran ante la embestida conservadora. Entre febrero y marzo de 2010, las Cámaras de Diputados y de Senadores aprobaron la iniciativa de reforma del artículo $40 \mathrm{de}$ la Constitución para establecer la laicidad como principio definitorio de la República Mexicana. Según la Comisión de Puntos Constitucionales de la Cámara de Diputados, este hecho reconocía de forma implícita la libertad de conciencia, de credo o de corriente filosófica, mediante la práctica individual o colectiva. Para la Comisión, la reforma evitaría que los valores o intereses religiosos se erigieran en parámetros para medir la legitimidad o justicia de las normas y actos de los poderes públicos e impediría desvíos entre las funciones religiosas y las

\footnotetext{
${ }^{15}$ Sobre la crítica a los funcionarios y a los resultados del gobierno de Calderón véase la nota en La Jornada, 9 de febrero de 2009. Respecto de las actividades del presidente panista en la Cumbre Mundial sobre Calentamiento Global véanse las declaraciones de Norberto Rivera en El Universal, 29 de noviembre de 2010. Sobre la discusión en torno a la educación véase la nota en La Jornada, 12 de septiembre de 2012.

${ }^{16} \mathrm{La}$ Comisión pasó la propuesta al pleno una vez que analizó las iniciativas presentadas por los diputados del PRI Alfonso Izquierdo Bustamante y César Augusto Santiago; del PRD Rafael García Tinajero y Víctor Hugo Círigo, y por Elsa Conde, del Partido Social Demócrata.
} 
funciones estatales. ${ }^{16}$ El texto del artículo 40 , validado por el Senado el 6 de noviembre de 2012, después de haber obtenido el voto de las legislaturas locales, quedó como sigue:

Es voluntad del pueblo mexicano constituirse en una República representativa, democrática, laica y federal, compuesta de Estados libres y soberanos en todo lo concerniente a su régimen interior, pero unidos en una federación establecida según los principios de esta ley fundamental (Reforma, 18 de febrero de 2010).

Un elemento clave que ha permitido cambios en distintos niveles de la vida nacional ha sido el reconocimiento de los derechos humanos en la Constitución. Desde algunos años atrás, la sociedad civil y varios diputados y senadores demandaron la actualización constitucional en esa materia, así como su armonización con los tratados internacionales. Después de un largo proceso de al menos siete años, que involucró varias iniciativas de algunos representantes ciudadanos e incluso del Ejecutivo Federal (Labardini, 2012: 320), en 2009 la Cámara de Diputados aprobó un proyecto de reforma sobre la base de un documento elaborado por la Secretaría de Gobernación. El texto tenía varias contradicciones, por lo que no se discutió en la Cámara de Senadores, pero las comisiones de Puntos Constitucionales, Estudios Legislativos y de Reforma del Estado del Senado trabajaron en una propuesta propia. El 10 de junio de 2011, después de seguir el proceso formal para su aprobación, fue publicada en el Diario Oficial de la Federación la reforma constitucional en materia de derechos humanos, que transformó el Capítulo I del Título Primero de la Constitución de la defensa "De las Garantías Individuales" a la promoción “De los Derechos Humanos y sus Garantías". La reforma fue considerada por varios juristas como la más significativa de los últimos 25 años (Becerril y Ballinas, 2011).

2011 fue un año álgido para la discusión entre los sectores liberales y conservadores del país. En diciembre hubo un nuevo embate por parte de un sector de los diputados del PRI y del PAN, que promovió una nueva modificación al artículo 24 constitucional, precepto que constituía el último candado para frenar la búsqueda de mayores privilegios por parte de la elite de la Iglesia católica. La iniciativa de ley para reformar el artículo 24 había sido presentada desde el 18 de marzo de 2010 por el diputado priista José Ricardo López Pescador. Los argumentos centrales derivaban de la argumentación que años antes se había tejido en ámbitos académicos, religiosos y políticos y a la que hice referencia en el apartado anterior. La idea toral era el intento de consolidación de un "Estado constitucional democrático de derecho", en el que - según el diputado- la libertad religiosa tenía una trascendencia jurídica por las siguientes razones: a) porque era uno de los derechos humanos y b) porque era necesario equiparar el tratamiento jurídico del acto social religioso, como ha ocurrido en otras sociedades occidentales y como lo marcan los tratados internacionales, en particular el Pacto Internacional de los Derechos Civiles y Políticos -artículo 18-, la Convención Americana sobre Derechos Humanos - artículo 12-, la Convención sobre los Derechos de la Niñez - artículo 14-, la Convención Internacional para la Eliminación de Todas las Formas de Discriminación Racial —artículo 5-, la Convención Interamericana para Prevenir, Suprimir y Erradicar la Violencia contra la Mujer -artículo 4- y la Convención sobre los Derechos de Todos los Trabajadores Migratorios - artículo 12-. En su exposición de motivos, el diputado enfatizó que el reconocimiento de la libertad religiosa implicaría, además, la aceptación de las fuentes de derecho positivo constitutivas de aquélla, mismas que, argumentó, han sido reconocidas por el derecho internacional. A saber:

1) La libertad de conciencia, que comprende el derecho a profesar en público o en privado la creencia religiosa que libremente se elija o simplemente no profesar ninguna; a cambiar o abandonar una confesión y a manifestar las propias creencias o la ausencia de las mismas. 
2) La libertad de culto, entendido como conjunto de actos y ceremonias a través de los cuales la persona rinde homenaje y celebra a una entidad superior.

3) La libertad de difusión de los credos, ideas u opiniones religiosas, mediante la que las personas pueden manifestar sus convicciones en formas diversas, desde reuniones privadas hasta públicas, pasando por la creación de centros educativos de formación religiosa y comunicación pública colectiva por medios electrónicos; específicamente este derecho transita y, por tanto, debería sujetarse a las mismas reglas que la libertad de expresión, cuya única restricción es respetar los demás derechos fundamentales de la persona o el individuo.

4) El derecho a la formación religiosa de los miembros de una iglesia, grupo o comunidad religiosa se traduce en el derecho a educar religiosamente.

5) El derecho a la educación religiosa, que consiste en la facultad y libertad de los padres para educar a sus hijos conforme a sus convicciones religiosas.

6) El derecho de asociación religiosa, que consiste en que toda persona tiene derecho a fundar asociaciones de carácter religioso o integrarse a las ya existentes (López, 2010).

De acuerdo con algunos especialistas en materia jurídica, la reforma de los artículos 24 y 130 realizada en 1992 había dado la pauta para reconocer lo religioso como un hecho social y, por tanto, eminentemente público, cuyas manifestaciones ameritaban un ordenamiento especial (Cerón, 2013: 52). Este marco argumentativo incluyó un elemento más de dificultad para los defensores de un principio de laicidad que esencialmente resaltaba la separación de los ámbitos de acción entre las iglesias y el Estado. Si el hecho religioso es un hecho social y, por tanto público, la clarificación y defensa de los límites entre ambas potestades se torna muchas veces un terreno pantanoso. Frecuentemente observamos la práctica de algún culto religioso por parte de algunos funcionarios en el contexto de actos públicos bajo el argumento de que no puede coartarse su derecho a ejercer plenamente la libertad de conciencia y la libertad de culto, como elementos indisolubles de la libertad religiosa. ${ }^{17}$ También hemos presenciado cómo algunos otros han invocado la libertad de conciencia para negarse a brindar sus servicios, por ejemplo médicos en relación con la práctica del aborto, lo que obstaculiza la instrumentación de acciones concretas que son parte de una política pública.

La tercera, cuarta y quinta dimensiones aludidas por el diputado López Pescador, relativas a la formación, educación y transmisión de un credo, evocaban el derecho de los padres a decidir sobre el tipo de educación que reciben sus hijos y en este sentido abrirían la posibilidad de demandar la enseñanza de una religión determinada en la escuela pública. Con la reivindicación de las dimensiones arriba señaladas se generaban condiciones para avanzar en el terreno de la posesión de medios de comunicación masiva, con base en el derecho de las iglesias a poseer un instrumento de socialización de su credo. Por último, la defensa de la capacidad de asociación aludía a la búsqueda de mayores espacios de representación a través, por ejemplo, de la formación de agrupaciones religiosas, las cuales eventualmente podrían llegar a convertirse en actores políticos importantes en coyunturas electorales. El diputado López Pescador elaboró un proyecto de decreto de reforma y adiciones al artículo 24, en los siguientes términos:

Artículo 24. Todo individuo tiene derecho a la libertad de conciencia y de religión; este derecho incluye la

\footnotetext{
${ }^{17}$ Los 12 años de gobierno panista a nivel federal fueron ejemplo de esta permanente violación a la ley. Recientemente se han agregado otros casos de funcionarios priistas y perredistas que han violentado el principio de laicidad. No obstante, los ejemplos más alarmantes durante el nuevo sexenio, que ahora aparecen como expresiones naturales de un sector del priismo, son los de los gobernadores de Chihuahua y Veracruz, César Duarte Jáquez y Javier Duarte Ochoa, respectivamente, quienes en actos públicos en su calidad de funcionarios encomendaron a las entidades que gobiernan a la protección de Dios. Los hechos ocurrieron después de haber sido elevado a rango constitucional la laicidad de la república.
} 
libertad de tener o adoptar, o no tener ni adoptar, la religión o las creencias de su elección, así como la libertad de manifestar su religión o creencias, individual o colectivamente, tanto en público como en privado, mediante el culto, la celebración de ritos, las prácticas, la difusión y la enseñanza; siempre que no constituyan un delito o una falta sancionados por la ley.

[...]

[Se deroga]

Sin contravenir lo prescrito en el artículo $3^{\circ}$ de esta Constitución, el Estado respetará la libertad de los padres y, en su caso, de los tutores legales para garantizar que los hijos reciban la educación religiosa y moral que esté de acuerdo con sus propias convicciones (López, 2010).

La Comisión de Puntos Constitucionales, integrada por 30 legisladores - 14 del PRI, nueve del PAN, cinco del PRD, uno del Partido Verde Ecologista de México (PVEM) y uno del Partido del Trabajo (РT)—, emitió un voto en sentido positivo y prácticamente retomó los principales argumentos que sustentaban la propuesta priista. El razonamiento de la Comisión

1) En el artículo $1^{\circ}$ de la Constitución, los derechos humanos se interpretan de conformidad con los tratados internacionales. Por lo que resulta necesario adecuar el contenido de las disposiciones fundamentales, a fin de armonizar el marco jurídico.

2) La Comisión coincide con la iniciativa en que la libertad religiosa es el complemento necesario del Estado laico. Éste no ignora la religiosidad del pueblo manifestada en la diversidad de creencias, la asume como un hecho social o cultural que toma en cuenta al momento de legislar o gobernar, para que la norma tenga eficacia. El Estado constitucional democrático es laico porque respeta la libertad de conciencia y de religión. Y agrega que, con la finalidad de ser consecuentes con la reforma aprobada al artículo 40 y respetar el contenido de los pactos internacionales de los que México es parte, se propone reformar el artículo 24 con el fin de reconocer expresamente la libertad religiosa en los mismos términos en que la reconocen y protegen los tratados de derechos humanos vigentes, especialmente el Pacto Internacional de Derechos Civiles y Políticos.

3) La Comisión valoró la posibilidad de avanzar en la materia de forma prudente, hasta donde las condiciones actuales y los compromisos de los grupos parlamentarios lo permitieron, toda vez que la libertad religiosa implica otros temas, sobre los que se debatirá en el futuro. Como por ejemplo, la libertad de conciencia en materia religiosa, la libertad de culto, la libertad de difusión de los credos, el derecho a la formación religiosa de los miembros de una iglesia, el derecho a la educación religiosa, el derecho a la asociación religiosa y la objeción de conciencia, que ha merecido una propuesta de la Conferencia del Episcopado Mexicano a ampliar su ámbito cuando la conciencia entra en conflicto ante posibles disposiciones legales en el campo de la salud, la biotecnología, la administración pública, en los medios de comunicación y en la labor educativa (Senado de la República, 2012).

El texto que la Comisión envió al pleno de la Cámara fue el siguiente:

Todo individuo tiene derecho a la libertad de conciencia y de religión, y a tener o adoptar, en su caso, la de su agrado. Esta libertad incluye el derecho a practicar individual o colectivamente, tanto en público como en privado, las ceremonias, devociones o actos del culto respectivo, siempre que no constituyan un delito o falta penados por la ley. Nadie podrá utilizar los actos públicos de expresión de esta libertad con fines políticos, de proselitismo o de propaganda política. [...]

[Se deroga] (Senado de la República, 2012).

Entre las reservas que se hicieron en el pleno destacan las siguientes: se pidió que se incluyera la idea de la libertad de convicciones éticas y la libertad de convicciones filosóficas. Se argumentó en el sentido de que ninguna iglesia debía gozar de privilegios. Se 


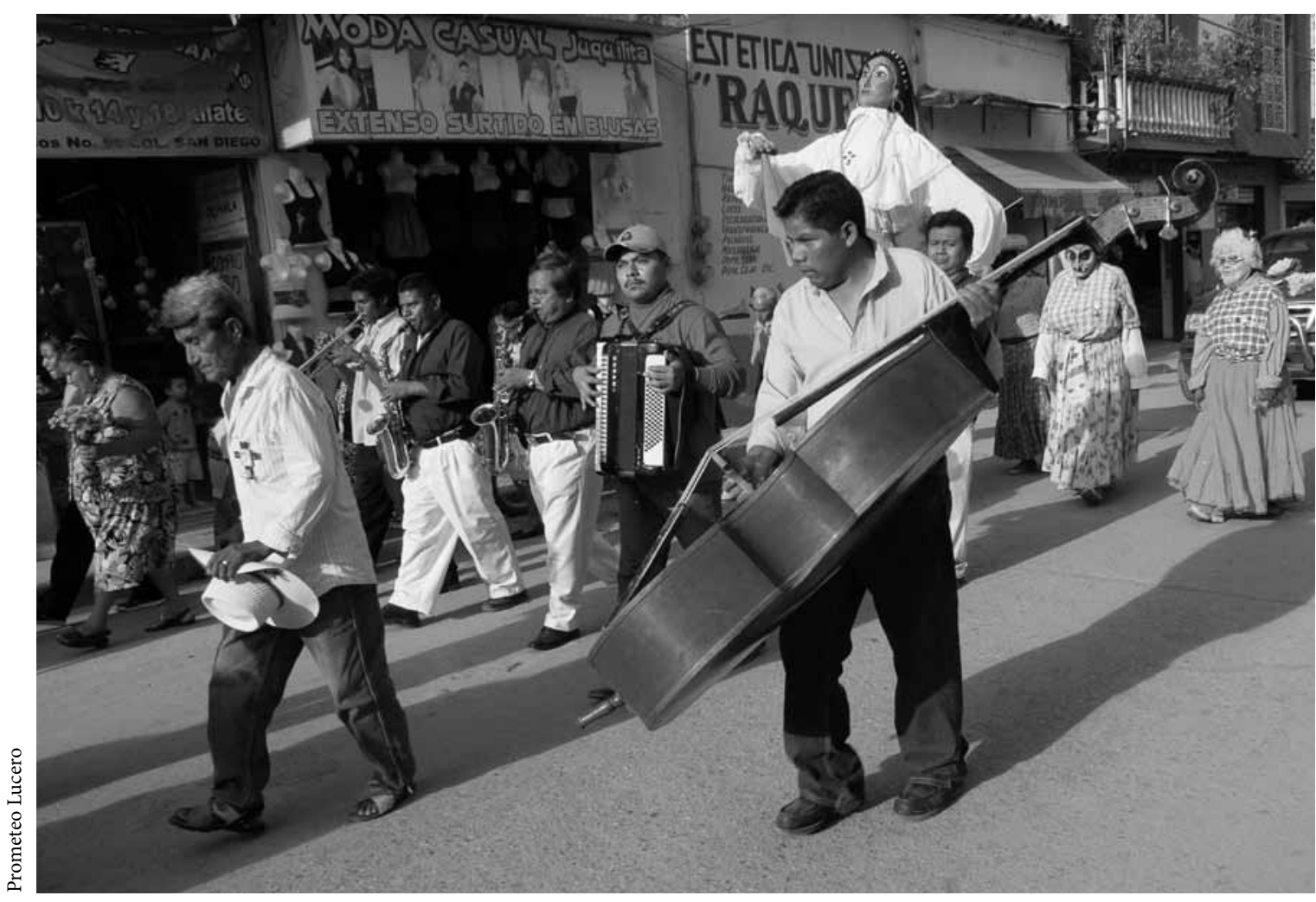

Festividad previa al Señor del Nicho en Tlapa, Guerrero.

estableció la igualdad jurídica entre personas con una confesión religiosa, ateos y agnósticos. Se hizo la diferencia entre los actos de culto público, ordinarios y extraordinarios. Finalmente fueron retomados los temas de las convicciones éticas y la diferenciación relativa a los actos de culto (Cerón, 2013: 59). La propuesta de reforma votada en la Cámara de Diputados y enviada al Senado fue la siguiente:

Artículo 24. Toda persona tiene derecho a la libertad de convicciones éticas, de conciencia y de religión, $y$ a tener o adoptar en su caso, la de su agrado. Esta libertad incluye el derecho de participar, individual o colectivamente, tanto en público como en privado, en las ceremonias, devociones o actos de culto respectivo, siempre que no constituyan un delito o falta penados por la ley. Nadie podrá utilizar los actos públicos de expresión de esta libertad con fines políticos, de proselitismo o de propaganda política. El Congreso no puede dictar leyes que establezcan o prohíban religión alguna. Los actos religiosos de culto público se celebrarán ordinariamente en los templos. Los que extraordinariamente se celebren fuera de éstos se sujetarán a la ley reglamentaria (Senado de la República, 2012).

Es necesario llamar la atención sobre el hecho de que desde el inicio del cabildeo de la reforma varios dirigentes evangélicos, los grupos masones, miembros de organizaciones de la sociedad civil en defensa del Estado laico y de los derechos humanos, así como algunos intelectuales se manifestaron contra la iniciativa. Destacaron que favorecía esencialmente a la Iglesia católica y vulneraba un principio fundamental del Estado mexicano. La coincidencia entre actores diversos contra la reforma quedó en evidencia con la publicación de algunos documentos que aparecieron en la prensa nacional, como el que llevó 
por título "La defensa del Estado laico, hoy más urgente que nunca", que apareció a principios de enero de 2012. Las manifestaciones opositoras siguieron aflorando en el marco de la visita del Papa Benedicto XVI al Bajío mexicano el 23 de marzo de ese año. Su viaje fue planeado en el arranque de las campañas electorales y, si bien sobre el tema en debate el pontífice se limitó a opinar que la libertad religiosa era un derecho universal, su presencia fue evidentemente un factor de presión para que la jerarquía católica mexicana y la elite política a favor de la reforma articularan las alianzas necesarias para su aprobación en el Congreso de la Unión. ${ }^{18}$

La minuta fue turnada a comisiones en el Senado de la República, donde las fracciones parlamentarias de los partidos realizaron varias reuniones de discusión con expertos en sociología de la religión, con estudiosos de la historia de la Iglesia católica en México, así como con representantes de la sociedad civil a favor y en contra de la reforma. ${ }^{19}$ No obstante, en los hechos éstas fueron sólo un trámite para la consolidación del proceso legislativo en el Congreso Federal, por lo que el 28 de marzo de 2012 el Senado ratificó sin modificaciones la propuesta enviada por la Cámara de Diputados. La negociación entre los impulsores y los opositores de los cambios se centró en aprobar tanto la reforma al 24 constitucional como los cambios al artículo 40, en enviar ambas iniciativas a los congresos locales y dejar que éstos enfrentaran las expresiones de descontento social.

En las marchas y plantones en oposición a la iniciativa aprobada en el Congreso de la Unión que se

\footnotetext{
${ }^{18}$ Para prevenir que la aprobación de la reforma se detuviera en el Senado, en abril también se propuso una iniciativa de cambios al artículo 76 de la Constitución. De haber prosperado el cambio al artículo 76 se hubiese eliminado la prerrogativa que tiene el Senado para vetar cualquier acuerdo que el presidente de México, en su calidad de jefe de Estado, pretenda concretar con los presidentes de otros países, lo que habría facilitado un posible acuerdo entre el Papa, como jefe del Estado Vaticano, y el presidente mexicano en turno.

${ }^{19}$ Según Bernardo Barranco, lo que apreciamos durante el proceso de cabildeo de la reforma fue el renacimiento de un "nuevo clericalismo", como de un "anticlericalismo", como rasgo del nuevo siglo (Barranco, 2012).
}

llevaron a cabo en más de 30 ciudades de entidades como Campeche, Veracruz, Tabasco, Quintana Roo, Guanajuato, Nuevo León, Puebla y el Distrito Federal participaron activamente miembros de las iglesias protestantes y evangélicas (Masferrer, 2013: 20). En varios casos, el descontento estuvo encabezado por el Foro Intereclesiástico Mexicano, asociación civil que reúne a más de cien asociaciones religiosas y cuyo objetivo es "impulsar el diálogo entre éstas y el Estado, reconocer la pluralidad religiosa y promover una cultura de respeto a las iglesias numéricamente minoritarias, además de denunciar la intolerancia y la discriminación de las autoridades, instituciones o personas que menoscaben el Estado laico y la libertad de creencias". ${ }^{20}$

\section{COMENTARIOS FINALES}

El contexto electoral de 2012 fue el marco propicio para la articulación de una nueva coalición conservadora, encabezada por miembros del PRI y del PAN, capaz de concretar cambios fundamentales en el contenido del principal marco normativo del país. La discusión sobre la reforma al artículo 24 constitucional cohesionó al panismo, dividió al priismo y paralizó al perredismo, que quedó muy desdibujado de la discusión. Como actor político, la Iglesia católica supo leer los tiempos electorales y el cambio en la correlación de fuerzas entre los dos principales partidos que disputaban la Presidencia de la República.

Para enero de 2013 la iniciativa de reforma del artículo 24 había sido aprobada en 16 legislaturas locales, ${ }^{21}$ y el 10 de mayo el Congreso del Estado de Jalisco avaló en comisiones los términos legales de la

\footnotetext{
${ }^{20}$ Véase <www.fim.org.mx $>$.

${ }^{21}$ En orden cronológico, las legislaturas que aprobaron la iniciativa de reforma fueron las de los siguientes estados: Estado de México, Hidalgo, Sonora, Durango, Coahuila, Querétaro, Chiapas, Chihuahua, Baja California Sur, Tlaxcala, Nuevo León, Nayarit, Campeche, Guanajuato, Puebla y Sinaloa.
} 
propuesta, con lo que los promotores de los cambios lograron consolidar la mayoría necesaria. Finalmente, el 19 de junio, la Comisión Permanente del Congreso de la Unión formuló la declaratoria de reforma del artículo 24 constitucional (Becerril y Ballinas, 2013). Ahora habrá que estar atentos a las implicaciones que tendrá la reforma en la Ley Reglamentaria del artículo 24 y en qué medida éstos podrían contravenir el espíritu laico que se consagró en el artículo 40.

En el esquema de la construcción de alianzas pragmáticas y ante la evidencia de que amplios sectores de la sociedad civil se manifestaron en contra, es claro que la contrarreforma religiosa fue una moneda de cambio útil básicamente para los miembros de la clase política, tanto para los que la impulsaron abiertamente como para los que optaron por un bajo perfil opositor. Pero en particular fue útil para el priismo que, con el apoyo implícito y explícito de un grupo importante de la alta jerarquía católica, logró ganar la elección presidencial, y para la Iglesia, que alcanzó su cometido y recuperó terreno en la escena pública, mostrando su lealtad al sistema y su utilidad para la refuncionalización del mismo en la línea de la política autoritaria y conservadora.

\section{BIBLIOGRAFÍA}

Armenta, Antonio, 1990, “Agustín Téllez Cruces, representante de CSG ante el Vaticano", en El Universal, 14 de febrero, México.

Barranco, Bernardo, 2012, "Neoanticlericalismo en México", en La Jornada, 1 de febrero, México.

Becerril, Andrea y Víctor Ballinas, 2011, "Aprobada, reforma constitucional en materia de derechos humanos", en La Jornada, 9 de marzo, México.

_ 2013, "Emiten declaratoria de la reforma al artículo 24", en La Jornada, 20 de junio, en línea: <http:// www.jornada.unam.mx/2013/06/20/politica/016n1 pol>, 20 de junio.

Blancarte, Roberto, 2004, Entre la fe y el poder. Política $y$ religión en México, Grijalbo, México.

Calderón Hinojosa, Felipe, 2009, "Discurso del presidente de México al inaugurar el Congreso de la familia”, en
Comisiones Vicaría de Pastoral, en línea: <http:// www.vicariadepastoral.org.mx/proyectos/EMF/congreso_teologico/congreso_teologico_04.htm $>$.

campeche.com.mx, 2012, "Iglesias marchan en contra del artículo 24", en línea: <http://www.campeche.com.mx/ noticias/campeche_noticias/iglesias-marchan-en-contra-del-articulo-24-en-riesgo-educacion-laica/44612>, 26 de noviembre.

Cerón, Adrián, 2013, "Reforma al artículo 24, la libertad ausente", en Elio Masferrer Kan (comp.), Estado laico y contrarreforma al 24 constitucional, Libros de la Araucaria, Red Nacional de Investigadores sobre Religión, Sociedad y Política, Universidad Autónoma de Querétaro, Buenos Aires.

Constitución Política de la República Mexicana de 1857, en línea: <http://www.juridicas.unam.mx/infjur/leg/conshist/pdf/1857.pdf $>$.

Constitución Política de los Estados Unidos Mexicanos, que reforma la de 5 de febrero de 1857, en línea: <http://www. juridicas.unam.mx/infjur/leg/conshist/pdf/1917.pdf>.

Foro Intereclesiástico Mexicano, 2012, "Rechaza Foro Intereclesiástico Mexicano reforma aprobada en el Senado sobre artículo 24 constitucional", en línea: <http://fim. org.mx/?p=320>, 30 de marzo.

González Schmal, Raúl, 1999, "Reformas y libertad religiosa en México", en Jaime Ruiz de Santiago et al., Libertad religiosa. Derecho humano fundamental, Instituto Mexi-

Hernández Vicencio, Tania, 2009, Tras las huellas de la derecha. El Partido Acción Nacional, 1930-2000, Ítaca, México.

_ 2011, "El Partido Acción Nacional en la lucha por la no despenalización del aborto en el Distrito Federal", en Andamios, vol. 8, núm. 15, enero-abril, Universidad Autónoma de la Ciudad de México, México.

— 2012 , "Elecciones 2010. El Partido Acción Nacional y sus bastiones electorales", en Rosa María Mirón y Francisco Reveles (coords.), Elecciones 2010. El mapa electoral, Universidad Nacional Autónoma de México, Instituto Federal Electoral, Instituto Electoral del Distrito Federal, México.

Instituto Nacional de Estadística y Geografía (INEGI), 2010, Censo de Población y Vivienda 2010, en línea: <http://www.censo2010.org.mx/>.

Labardini, Rodrigo, 2012, "Proteo en México. Un nuevo paradigma: derechos humanos y Constitución”, en Boletín Mexicano de Derecho Comparado, Nueva Serie, año XLV, núm. 133, enero-abril, Universidad Nacional Autónoma de México, México, pp. 319-353.

Loaeza, Soledad, 1996, "Las relaciones Estado-Iglesia católica en México, 1988-1994. Los costos de la 
institucionalización", en Foro Internacional, núm. 36, El Colegio de México, enero-junio.

López Pescador, José Ricardo, 2010, "Proyecto de decreto que reforma el artículo 24 de la Constitución Política de los Estados Unidos Mexicanos, a cargo del Diputado José Ricardo López Pescador, del grupo parlamentario del PRI", Cámara de Diputados, en línea: <http:// www.diputados.gob.mx/articulo24/docs/anexo3.pdf >.

Masferrer, Elio, 2000, "Entre la visita del Papa y las expectativas del apocalipsis: un análisis del campo religioso mexicano 1999-2000", en Revista Académica para el Estudio de las Religiones, Ritos y Creencias del Nuevo Milenio, t. III, cap. 13, Asociación Latinoamericana para el Estudio de las Religiones, pp. 263-285, en línea: <http://www.revistaacademica.com/TIII/Capitulo_13.pdf, 20 de mayo de 2013>.

_, 2013, "El impacto sociopolítico y cultural de los cambios al artículo 24 constitucional", en Elio Masferrer Kan (comp.), Estado laico y contrarreforma al 24 constitucional, México, Libros de la Araucaria, Red Nacional de Investigadores sobre Religión, Sociedad y Política, Universidad Autónoma de Querétaro, Buenos Aires.

Mendoza, Diana Anabel, 1989, "Meta de la Iglesia: libertad para la prédica de un evangelio crítico", en El Universal, 10 de junio, México.

Molina Meliá, Antonio, 1999, "El Estado moderno y la libertad religiosa", en Jaime Ruiz de Santiago et al., Libertad religiosa, Instituto Mexicano de Doctrina Social Cristiana, México.
Mosca, Gaetano, 1986, La clase política, Fondo de Cultura Económica, México.

noticiacristiana.com, 2012, "Evangélicos mexicanos rechazan reforma al artículo 24 de la Constitución”, en línea: $<$ http://www.noticiacristiana.com/sociedad/iglesia estado/2012/02/evangelicos-mexicanos-rechazanreforma-al-articulo-24-de-la-constitucion.html>, 2 de febrero.

Reforma, 18 de febrero de 2010, Sección Nacional, p. 2.

Ríos, Julio, 2013, "Jalisco aprueba reforma al artículo 24 en comisiones", en La Jornada de Jalisco, en línea: $<$ http://www.lajornadajalisco.com.mx/2013/04/23/ jalisco-aprueba-reforma-al-articulo-24-en-comisiones/>, 24 de abril, Guadalajara.

Salas Hernández, Javier, 2013, "Masones exigen al Congreso del Estado votar en contra de la reforma al artículo 24", en Al Calor Politico, en línea: <http://www.alcalorpolitico.com/informacion/masones-exigen-al-congreso-del-estado-votar-en-contra-de-la-reforma-al-articulo-24-106823.html\#.UZ-uDUpZ5-g>, 2 de enero.

Samaniego, Fidel y Enrique Aranda, 1988, "Modernizar relaciones con la Iglesia, propone CsG", en El Universal, 2 de diciembre, México.

Senado de la República, 2012, "Dictámenes a Discusión y Votación. De las Comisiones Unidas de Puntos Constitucionales y de Estudios Legislativos, que contiene proyecto de decreto por el que se reforma el primer párrafo del artículo 24 de la Constitución Política de los Estados Unidos Mexicanos", en <http://www.senado.gob.mx/ index.php?ver $=$ sp\&mn=2\&sm $=2 \& i d=13893>$. 